\title{
Application of a Multienzymatic System from Natural Latex in Key Reactions for oil-Based Biorefineries
}

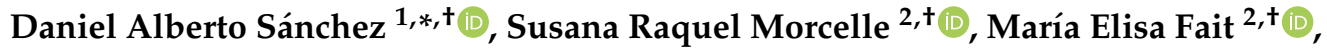 \\ Gabriela Marta Tonetto ${ }^{1,+}$ and María Luján Ferreira ${ }^{3,+}$ \\ 1 Departamento de Ingeniería Química, Universidad Nacional del Sur (UNS), Planta Piloto de Ingeniería \\ Química-PLAPIQUI (UNS-CONICET), Bahía Blanca 8000, Argentina; gtonetto@plapiqui.edu.ar \\ 2 Centro de Investigación de Proteínas Vegetales (CIPROVE-UNLP-Centro Asociado CICPBA), \\ Departamento de Ciencias Biológicas, Facultad de Ciencias Exactas, Universidad Nacional de La Plata, \\ La Plata 1900, Argentina; morcelle@biol.unlp.edu.ar (S.R.M.); fait.mariaelisa@biol.unlp.edu.ar (M.E.F.) \\ 3 Departamento de Química, Universidad Nacional del Sur (UNS), Planta Piloto de Ingeniería \\ Química-PLAPIQUI (UNS-CONICET), Bahía Blanca 8000, Argentina; mlferreira@plapiqui.edu.ar \\ * Correspondence: dsanchez@plapiqui.edu.ar; Tel.: +54-291-4861700 \\ + Consejo Nacional de Investigaciones Científicas y Técnicas (CONICET), Buenos Aires, Argentina.
}

Received: 29 December 2018; Accepted: 29 January 2019; Published: 2 February 2019

\begin{abstract}
Oil-based biorefineries play a crucial role in the production of key platform chemicals that can be generated via biotechnological processes instead of a petrochemical route. This work focuses on the latex of the fruit of Araujia sericifera, which can be considered a multienzymatic system with applications in key reactions in oil-based biorefineries. The latex of Araujia sericifera (ASL) was used as a novel biocatalyst in the esterification of oleic acid and in the hydrolysis of triglycerides and $p$-nitrophenyl carboxylates. When ASL was compared to a commercial biocatalyst, it showed an excellent activity in the hydrolysis of soybean oil and $p$-nitropheyl laurate, and a comparable activity in the esterification reaction.
\end{abstract}

Keywords: Araujia sericifera; latex; lipase; esterification; hydrolysis; oil-based biorefinery

\section{Introduction}

A biorefinery is the integral upstream, midstream, and downstream sustainable processing of biomass in order to generate a variety of products [1]. The physical and chemical nature of the raw material, besides the economic interest, is the key to predict the products. However, they may be widely different in yield and distribution depending on the characteristics of the biomass. Biorefineries can be used in integrated production configurations to produce value-added products from oleo-chemical feedstock, besides animal fats [2].

Biorefining has large capital expenditure (CAPEX) and requires full knowledge of the feedstock that should be low-cost and easy to obtain to support a facility. Historically there have been first, second and third generation of feedstock. The first generation is food crops as feedstock. Bioethanol can be produced from sugarcane, sugarbeet, sweet sorghum and starch (corn) crops, while biodiesel is obtained from oil seed crops (e.g., soybean, oil palm, rapeseed, and sunflower). The second generation involved non-food crops and lignocellulosic wastes. The feedstock may include non-food, short rotation grasses, agricultural residues and agroindustrial wastes. Finally, the third generation is non-food marine biomass (algae, spanning macroalgae or seaweed, and microalgae) [3].

In an oil-based (or oleochemical) biorefinery, the feedstock is oil-rich; therefore, it could be oil crops biorefinery or animal fat biorefinery. Usually, biodiesel is mentioned as the main product; however, many other alkyl esters are products with added-value obtained. Even more, fatty acids, 
fatty alcohols, partial glycerides, glycerol, and fatty amines are oleochemical compounds of great importance that can be produced from oils and fats. All of them are analyzed when studying the potential of an oil-based refinery.

Soy, palm, coconut, sunflower, peanuts, and corn are the main sources of vegetable oils. The reactions to be considered in an oil-based biorefinery to obtain the desired products include hydrolysis, alcoholysis, glycerolysis, esterification, interesterification, and transesterification [4]. These reactions can be carried out using inorganic chemical catalysts or enzymes [5].

Most reactions catalyzed by enzymes are more selective and produce fewer unwanted products than reactions catalyzed by inorganic chemical compounds. However, the use of enzymes in the commodity-based industry (for example the biodiesel industry) is limited due to their higher cost. The expansion of enzymatically catalyzed processes depends on the finding of new enzymes with high activity and low costs.

In the field of oleochemistry, lipases and phospholipases are the most important enzymes [6]. However, the high cost of commercially available lipases makes them prohibitive for a large number of industrial processes. Obtaining new enzymes by genetic engineering, protein engineering or metagenomics is still expensive. Within this context, plants are presented as low-cost and easily accessible sources of enzymes [7].

Araujia sericifera is a subarbustive climbing plant native to South America. This plant is characterized by having a milky sap (latex) and has been used as a medicinal and ornamental plant [8]. The study of enzymes from plant sources of the Araujia genus has focused on the characterization of hydrolytic activity associated with cysteine-peptidases [9-11]. The synthesis of dipeptides [9], surfactants [10], and esters [12] using an Araujia extract has been reported. The proteases of the soluble fraction of the Araujia extract have been isolated and characterized [11] and the lipase activity of the insoluble fraction was evaluated in some test reactions [13]. However, integral study of the use of the latex from Araujia's fruit is very uncommon.

In the latex of lacticiferous plants, proteins, alkaloids, starches, sugars, oil, tannins, resins, and gums among other compounds could be found. This complex system may naturally include enzymes with different properties and activities. Latex has a water-insoluble fraction. Some enzymes could be potentially immobilized by strong chemical bonds or physical binding to the different compounds present in the fraction of the latex. In this way, this natural biocatalyst is insoluble in water and in various organic solvents. Different research groups around the world have considered the enzymes present in plant latex as "self-supporting" enzymes [7]. The characterization of these systems is complex and during the isolation process the deactivation of the enzymes present can be observed. For this reason, latex could be used as a complete system. The activity obtained in the different reactions is assigned to the global system that contains multiple enzymes.

Consequently, the latex from Araujia sericifera has great potential for multiple applications in oil-based biorefineries, considering that is a low cost source of self-immobilized enzymes (such as lipases, phospholipases and proteases). Not only the traditional routes of hydrolysis of oils, triglycerides, and phospholipids are fields for the application of enzymes, they can be also used as catalysts in the esterification of fatty acids and the reactions of glycerol in order to produce high added-value products such as glycerol carbonate, acrolein or cyclic acetals. Besides, other non-traditional fields of application are the enzymatic synthesis of triacetin and structured mono or diglycerides or the enzymatic polymerization of diacids or diacids with poliols to obtain biodegradable polymers. In addition, due to the inherent complexity of this natural product, it may contribute also to protein degradation through peptidase activity and to phospholipids removal due to phospholipase activity. Bearing this in mind, the latex of Araujia sericifera is the source of a low-cost biocatalyst with the potential of multiple applications in biorefineries and the promise of an open door to further optimization for the industrial scaling.

In this work, we will focus on the use of the latex from Araujia sericifera or ASL, which can contain multiple enzymes, as a biocatalyst in three key reactions for oil-based biorefineries: Fatty acid 
esterification and hydrolysis of triglycerides and p-nitrophenyl carboxylates. A comparison with commercial biocatalysts shows how competitive the performance of ASL is in selected reactions.

\section{Materials and Methods}

\subsection{Materials}

Lipozyme RM IM (lipase from Rhizomucor miehei immobilized on Duolite A-568) and Lipozyme TL IM (lipase from Thermomyces lanuginosus immobilized on an acrylic resin) were kindly providedby Novo Nordisk A/S (São Paulo, Brazil). Novozym 435, which is a commercial form of the lipase B from Candida antarctica immobilized on a macroporous resin, was kindly provided by Novozyme (Bagsvaerd, Denmark, Brazil branch office). n-Heptane was supplied by Laboratorios Cicarelli (San Lorenzo, Santa Fe, Argentina). Absolute ethanol, 1-propanol, and ethyl ether were obtained from Dorwil (San Isidro, Buenos Aires, Argentina). 1-Butanol was purchased from Merck and 1-pentanol, 1-hexanol, 1-heptanol, 1-octanol, p-nitrophenyl laurate, and p-nitrophenyl palmitate were supplied by Sigma-Aldrich (St. Louis, MI, USA). Phenolphthalein was provided by Anedra S.A. (Buenos Aires, Argentina). All the reagents were of analytical grade.

\subsection{Araujia Sericifera Latex (ASL) Extraction}

The extraction of the latex from Araujia sericifera was conducted following the methodology reported by Di Santo Meztler et al. [13] but using oven-drying instead of lyophilization. For this purpose, the unripe Araujia sericifera fruits were collected at the end of summer in natural plantations of the rural area of Salliqueló, Province of Buenos Aires, Argentina ( $36^{\circ} 45^{\prime} 00^{\prime \prime} \mathrm{S}, 62^{\circ} 55^{\prime} 59^{\prime \prime} \mathrm{W}$ ). The latex was obtained by removal of the petioles of the fruit and by collection in a solution containing $5 \mathrm{mM}$ ethylen diamine tetracetic acid (EDTA) kept in an ice bath. The homogenate was centrifuged (8000 rpm, $15 \mathrm{~min}$ ) to separate the insoluble fraction (gums) from the soluble fraction. The insoluble fraction obtained was dried in an oven at $40^{\circ} \mathrm{C}$ and then weighed. This dry solid was called latex from Araujia sericifera (or ASL) from now on. The dry latex was stored at $4{ }^{\circ} \mathrm{C}$ until its use.

\subsection{Esterification of Oleic Acid with Different Alcohols}

The esterification of oleic acid (OA) was carried out with alcohols with different lengths of their carbon chains. For this, $1 \mathrm{mmol}$ of OA, $2 \mathrm{mmol}$ of alcohol, and $1 \mathrm{~mL}$ of $\mathrm{n}$-heptane were placed in a $10 \mathrm{~mL}$ vial. The vial was placed in a thermostatic bath at $30^{\circ} \mathrm{C}$ and once reached the temperature the reaction was started with the addition of the biocatalyst (ASL) in a proportion of $10 \%$ with respect to the mass of oleic acid. The reaction time was $5 \mathrm{~h}$ and magnetic stirring at $600 \mathrm{rpm}$ was used. The reaction was stopped with the addition of $2 \mathrm{~mL}$ of an absolute ethanol:ethyl ether 1:1 $(v / v)$ solution and the biocatalyst was separated by centrifugation.

In order to study the effect of the reaction temperature on the esterification catalyzed by ASL, the esterification of OA and 1-octanol (OL) was carried out as described above, but in this case varying the reaction temperature between 20 and $60^{\circ} \mathrm{C}$. The biocatalyst loading was studied with the same reaction performed at $30^{\circ} \mathrm{C}$ and the biocatalyst mass was varied between 2.5 and $17.5 \%$ with respect to the mass of OA to determine the optimum mass thereof. Variation of the ratio OA/OL was also studied. The esterification of oleic acid and 1-octanol was carried out as described above but varying the molar ratio of the substrates. In all cases $1 \mathrm{mmol}$ of $\mathrm{OA}$ was used and the initial molar ratio OA/OL was varied from 1:1 to 1:4.

In order to compare the performance of ASL in the esterification reaction with commercial biocatalysts, the esterification of OA and 1-pentanol was studied using as catalysts: ASL, Novozym 435, Lipozyme RM IM and Lipozyme TL IM. For this, $1 \mathrm{mmol}$ of OA, $2 \mathrm{mmoL}$ of 1-pentanol, and $1 \mathrm{~mL}$ of $\mathrm{n}$-heptane were placed in a $10 \mathrm{~mL}$ vial. The vial was placed in a thermostatic bath at $30{ }^{\circ} \mathrm{C}$ and once it reached temperature, the reaction was started with the addition of $15 \%$ of biocatalyst (regarding the mass of OA). The reaction time was $5 \mathrm{~h}$ and magnetic stirring at $600 \mathrm{rpm}$ was used. 
All the reactions were made in duplicate, and the reported results correspond to the mean along with the standard error. A simple ANOVA procedure was performed to determine the effect of various parameters on the conversion of oleic acid. To determine significant differences between values of the means, multiple range tests were performed (Supplementary Material). Titration of the samples was performed with ethanolic $0.06 \mathrm{M}$ potassium hydroxide to determine the amount of the remaining acid. Phenolphthalein was used as indicator. The oleic acid conversion was obtained with an error of \pm 1 percentage point with the following equation:

$$
X_{O A}=\frac{O A_{I}-O A_{F}}{O A_{I}} \times 100
$$

where $O A_{I}$ are the mmoles of oleic acid at the beginning of the reaction and $O A_{F}$ are the mmoles of oleic acid after $5 \mathrm{~h}$ of reaction.

\subsection{Hydrolysis of Soybean Oil Catalyzed by ASL}

The hydrolysis of soybean oil was carried out using different oil/water molar ratios. For this, $1 \mathrm{mmoL}$ of soybean and $1 \mathrm{~mL}$ of $\mathrm{n}$-heptane were placed in a $10 \mathrm{~mL}$ vial. The vial was placed in a thermostatic bath at $30^{\circ} \mathrm{C}$, and once it reached temperature, the reaction was started with the addition of the biocatalyst (ASL) in a proportion of $10 \%$ with respect to the mass of soybean oil. The reaction time was $5 \mathrm{~h}$ and magnetic stirring at $600 \mathrm{rpm}$ was used. The reaction was stopped with the addition of $2 \mathrm{~mL}$ of an absolute ethanol/ethyl ether 1:1 $(v / v)$ solution and the biocatalyst was separated by centrifugation.

In order to evaluate the effect of the temperature on the soybean oil hydrolysis, the described reaction was carried out between 20 and $60^{\circ} \mathrm{C}$.

The effect of the ASL loading on the hydrolysis of soybean oil was also evaluated. Biocatalyst masses comprised between 2.5 and $15 \%$ with respect to the mass of soybean oil (temperature: $30{ }^{\circ} \mathrm{C}$ and for a molar ratio oil/water 1:9 moL/moL) were tested according to the methodology already described.

The performance of ASL in soybean oil hydrolysis reaction was compared with the following commercial biocatalyst: Novozym 435, Lipozyme RM IM and Lipozyme TL IM. The reaction was performed as indicated above, using $15 \%$ of biocatalyst (based on soybean oil mass).

All the reactions were carried out in duplicate, and the reported results correspond to the mean along with the standard error. A simple ANOVA procedure was performed to determine the effect of various parameters on the yield to free fatty acids. To determine significant differences between values of the means, multiple range tests were performed (Supplementary Material). Titration of the samples was performed with ethanolic $0.06 \mathrm{M}$ potassium hydroxide to determine the amount of free fatty acids (FFA). Phenolphthalein was used as indicator. The yield to free fatty acids acid was obtained with an error less than $1 \%$ with the following equation:

$$
Y_{F F A}=\frac{F F A_{F}}{F F A_{\text {Theoretical }}} \times 100
$$

where $F F A_{F}$ are the mmoles of free fatty acids at $5 \mathrm{~h}$ of reaction and $F F A_{\text {Theoretical }}$ are the mmoles of free fatty acids if the total conversion of the oil with $100 \%$ selectivity to free fatty acids occurred.

\subsection{Hydrolysis of p-Nitrophenyl Esters}

The reactions were carried out following the methodology described by Rashid et al. [14] with slight modifications. The $p$-nitropheyl esters chosen for the analysis were laurate and palmitate (Sigma). An aliquot $(50 \mu \mathrm{L})$ of substrate stock solution $(0.88 \mathrm{mM}$ for palmitate and $0.91 \mathrm{mM}$ for laurate) prepared in a mixture of acetonitrile/isopropanol (1:4) was added to the reaction medium (final concentration: $0.044 \mathrm{mM}$ and $0.045 \mathrm{mM}$ respectively) which contained Tris- $\mathrm{HCl}$ buffer $(0.1 \mathrm{M}, \mathrm{pH} 8.0$ with Triton $\mathrm{X}-1000.0075 \% v / v), \mathrm{CaCl}_{2}$ ( $5 \mathrm{mM}$ in the reaction medium) and the biocatalyst. The reaction was 
conducted with magnetic stirring using a heating jacket at $30^{\circ} \mathrm{C}$. The biocatalyst's masses and the time of reaction were adjusted for each substrate: For palmitate, the biocatalyst mass tested was $2.5 \mathrm{mg}$ and the reaction time was $10 \mathrm{~min}$, whereas for laurate they were $5 \mathrm{mg}$ and $6 \mathrm{~min}$, respectively. At the end of the reaction, samples were collected and filtered through a nylon membrane (Osmonics) to remove the biocatalyst, and the absorbance of the filtrate was measured at $405 \mathrm{~nm}$. Blank reactions were performed to consider the appearance of the product due to the spontaneous hydrolysis of the substrate. In all cases, the enzyme activity was calculated as international units (IU, 1 IU being the amount of enzyme that liberates 1 micromole of $p$-nitrophenol per min under the assay conditions). To this end, a calibration curve with $p$-nitrophenol dissolved in the reaction buffer was carried out.

\section{Results}

\subsection{Esterification of Oleic Acid Catalyzed by ASL}

The esterification of oleic acid catalyzed by ASL was studied using alcohols with different carbon (C) chain lengths. Ethanol, 1-propanol, 1- butanol, 1-pentanol, 1-hexanol, 1-heptanol and 1-octanol were analyzed. Figure 1 shows the conversion of $\mathrm{OA}$ with the different alcohols. The conversion was higher than $60 \%$ for alcohols with C chain-length greater than 5 C, and lower than $30 \%$ for ethanol, 1-propanol and 1- butanol.

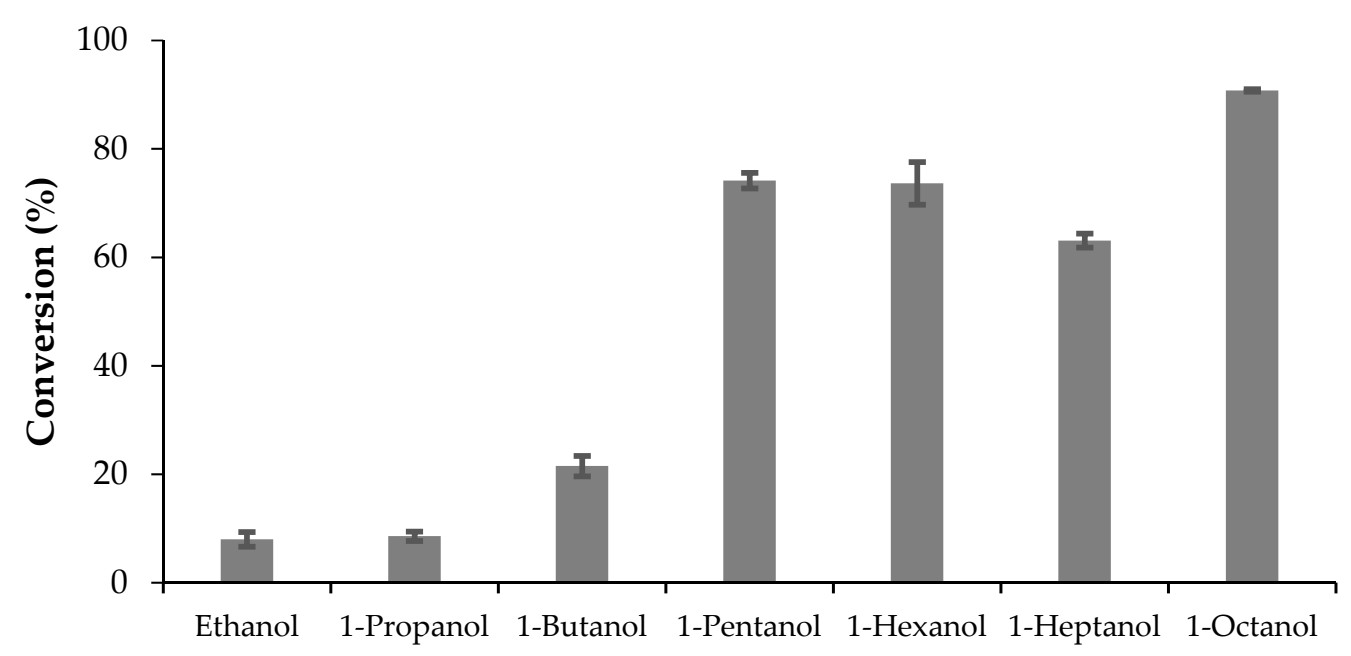

Alcohol

Figure 1. Esterification of $\mathrm{OA}$ with alcohols with different length of carbon chain. Reaction conditions: $1 \mathrm{mmol}$ of OA, $2 \mathrm{mmoL}$ of alcohol, $1 \mathrm{~mL}$ n-heptane, $30{ }^{\circ} \mathrm{C}, 5 \mathrm{~h}$, and $10 \%$ of biocatalyst based on OA mass.

The effect of the reaction temperature on the esterification activity of OA with 1-octanol catalyzed by ASL was studied in the range $20-60^{\circ} \mathrm{C}$. Figure 2 presents the results. An optimal conversion was observed between 30 and $40{ }^{\circ} \mathrm{C}$. 


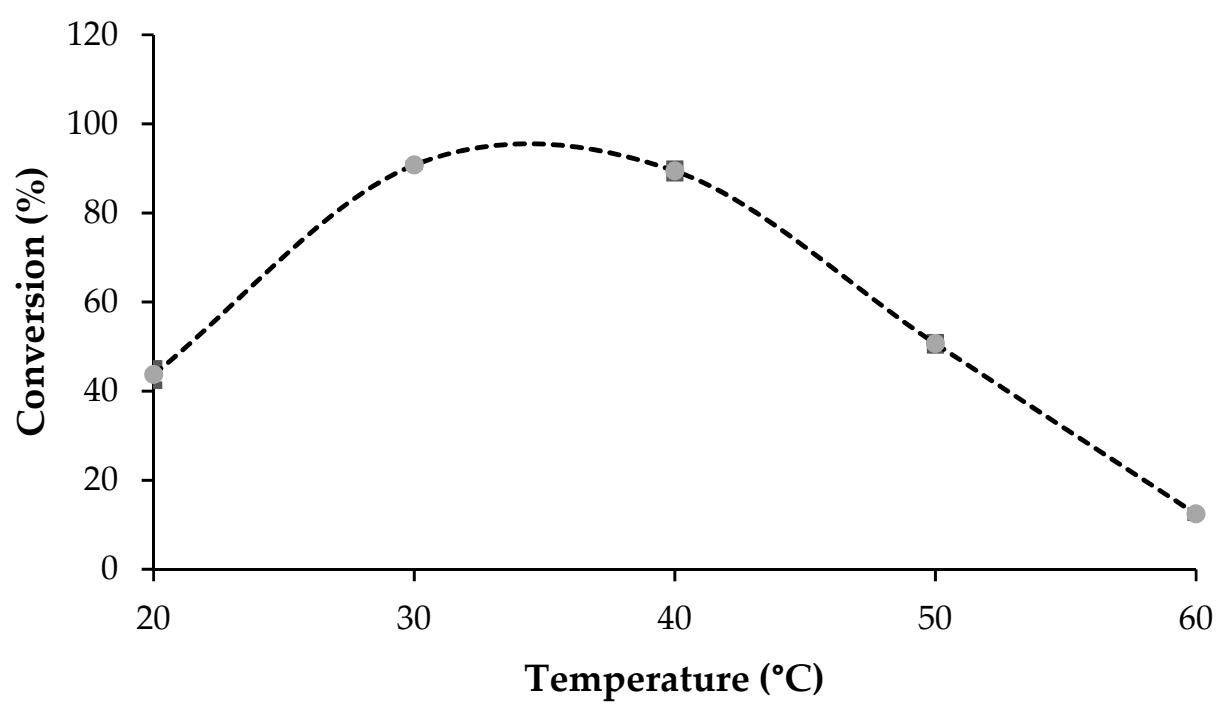

Figure 2. Esterification of $\mathrm{OA}$ and 1-octanol at different reaction temperatures. Reaction conditions: 1 $\mathrm{mmoL}$ of OA, $2 \mathrm{mmoL}$ of 1 -octanol, $1 \mathrm{~mL}$-heptane, $5 \mathrm{~h}$, and $10 \%$ of biocatalyst based on OA mass.

The optimum biocatalyst loading for esterification OA with 1-octanol was studied adjusting the ASL mass in the range $0-17.5 \%$ based on OA mass. Figure 3 presents the results and shows a constant OA conversion ( $\sim 90 \%)$ when $10 \%$ or higher concentration of ASL was used.

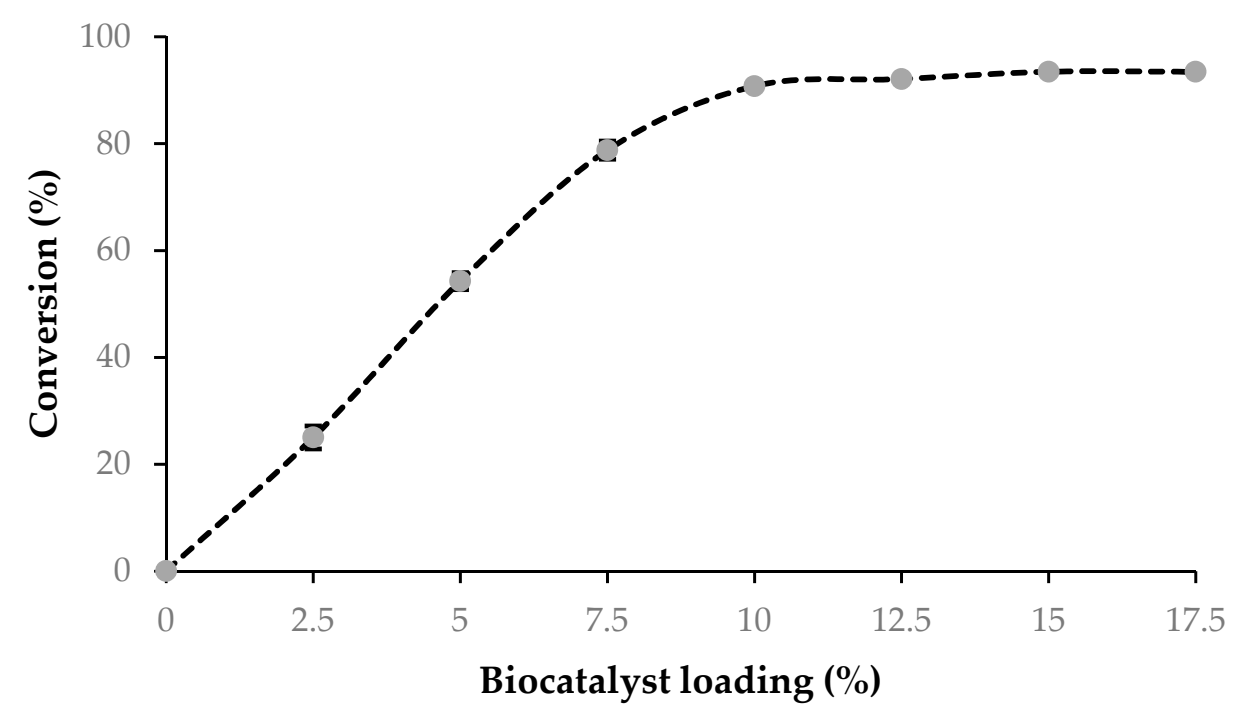

Figure 3. Esterification of $\mathrm{OA}$ and 1-octanol using different biocatalyst loading. Reaction conditions: 1 mmol of $\mathrm{OA}, 2 \mathrm{mmoL}$ of 1 -octanol, $1 \mathrm{~mL}$-heptane, $30^{\circ} \mathrm{C}$, and $5 \mathrm{~h}$.

The effect of the initial molar ratio between reactants on the esterification activity of OA with 1-octanol catalyzed by ASL was studied in the range acid/octanol molar ratios from 1:1 to 1:4. Figure 4 presents the results. An optimal conversion can be observed for the ratio OA/OL 1:2. 


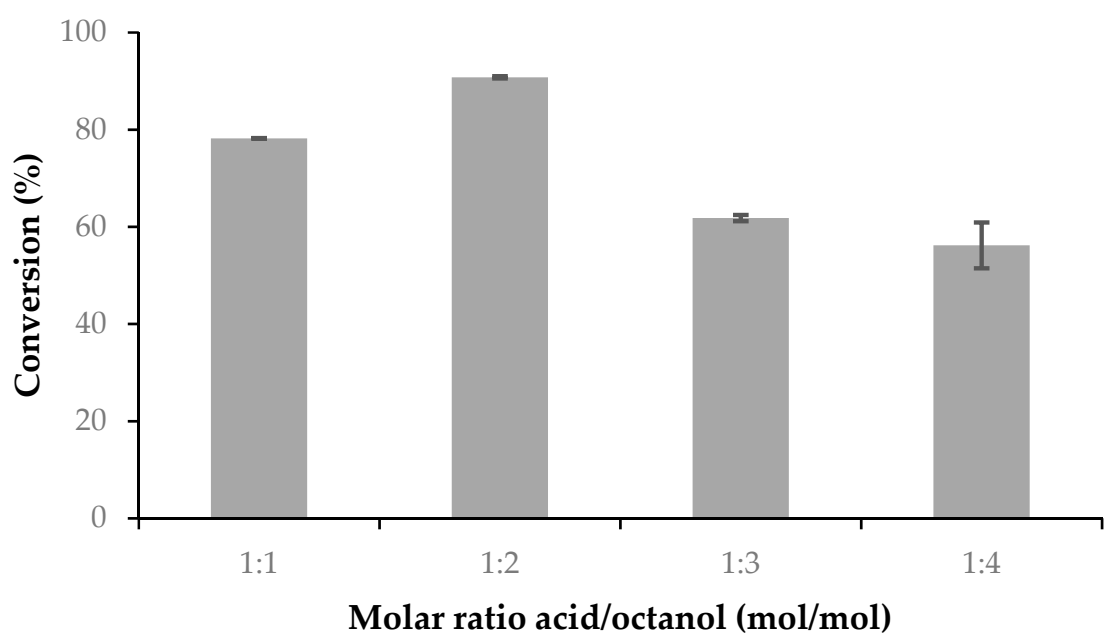

Figure 4. Esterification of $\mathrm{OA}$ with 1-octanol with different acid/octanol molar ratios. Reaction conditions: $1 \mathrm{mmol}$ of OA, $1 \mathrm{~mL}$-heptane, $10 \%$ of biocatalyst based on OA mass, $30^{\circ} \mathrm{C}$, and $5 \mathrm{~h}$.

The esterification reaction between oleic acid and 1-octanol as a function of time was carried out under the optimum conditions previously found (initial molar ratio OA/OL: 1:2, 10\% of biocatalyst, $30^{\circ} \mathrm{C}$ ). Figure 5 shows the conversion of oleic acid as a function of the reaction time. The highest OA conversions ( $90 \%)$ were observed after $4 \mathrm{~h}$.

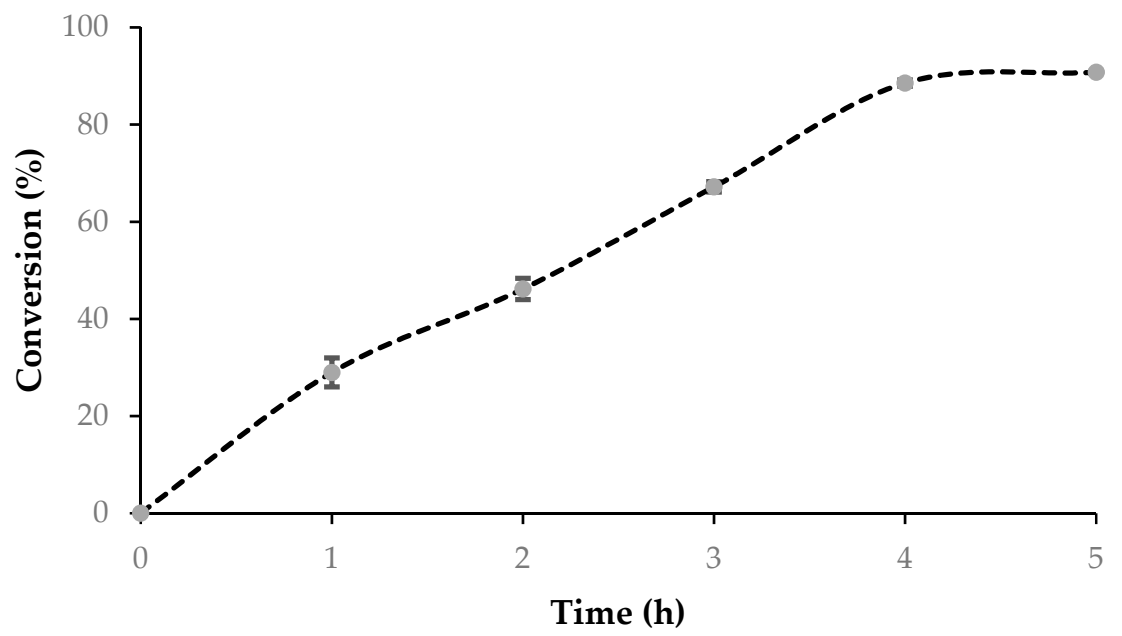

Figure 5. Esterification of oleic acid with 1-octanol under optimal conditions. Evaluation of the reaction time. Reaction conditions: $1 \mathrm{mmoL}$ of oleic acid, $2 \mathrm{mmoL}$ of 1 -octanol, $1 \mathrm{~mL}$-heptane, $10 \%$ of biocatalyst based on $\mathrm{OA}$ mass, and $30^{\circ} \mathrm{C}$.

The esterification of $\mathrm{OA}$ and 1-pentanol was the test reaction chosen for comparing the performance of ASL with that of commercial biocatalysts as indicated in the Materials and Methods Section. Figure 6 shows the evolution of OA conversion with the reaction time. The three commercial biocatalysts showed their highest conversion ( 93\%) after $2 \mathrm{~h}$. At that time, the activity of ASL was $82 \%$, and it achieved its highest conversion ( 91\%) after $5 \mathrm{~h}$. 


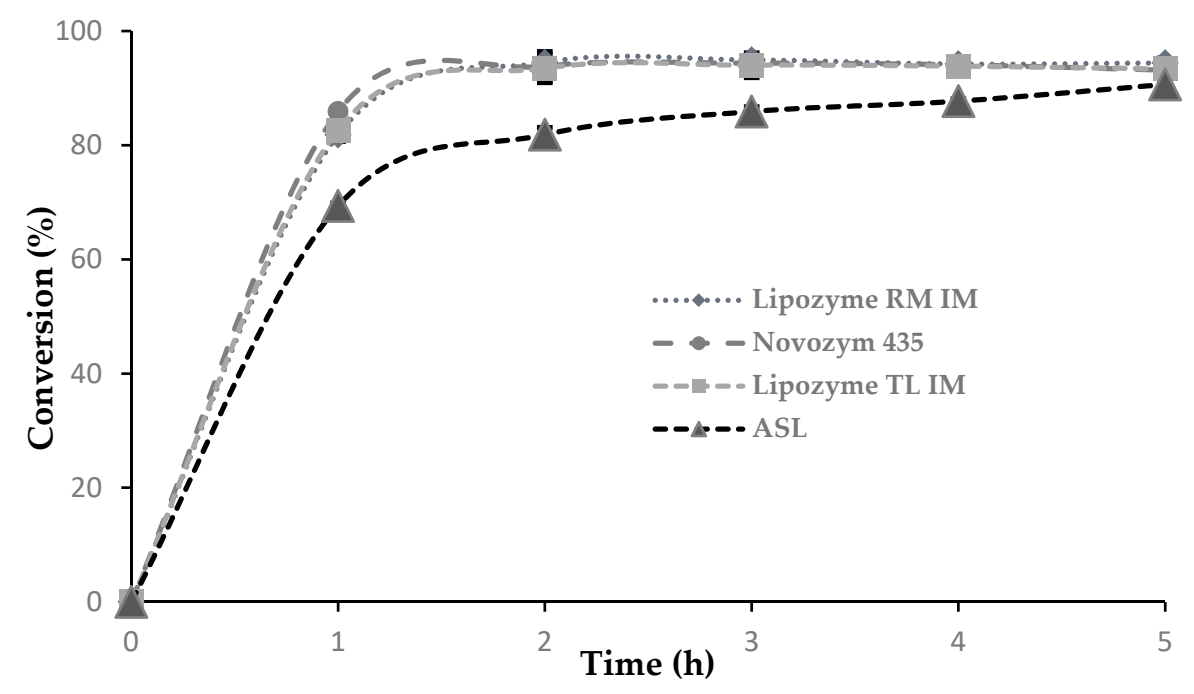

Figure 6. Esterification of $\mathrm{OA}$ and 1-pentanol using different biocatalyst. Reaction conditions: $1 \mathrm{mmoL}$ of OA, $2 \mathrm{mmoL}$ of 1-pentanol, $1 \mathrm{~mL}$-heptane, $15 \%$ of biocatalyst based on OA mass, and $30{ }^{\circ} \mathrm{C}$. Biocatalyst: ASL, Novozym 435, Lipozyme RM IM, Lipozyme TL IM.

\subsection{Hydrolysis of Soybean Oil Catalyzed by ASL}

The hydrolysis of soybean oil catalyzed by ASL was studied using different initial oil/water ratios. Figure 7 shows the yield to fatty acids when the initial oil/water molar ratios was varied in the range $1: 3$ to $1: 12$. The ratios $1: 9$ and $1: 12$ showed the same yield to fatty acids $(68 \%)$.

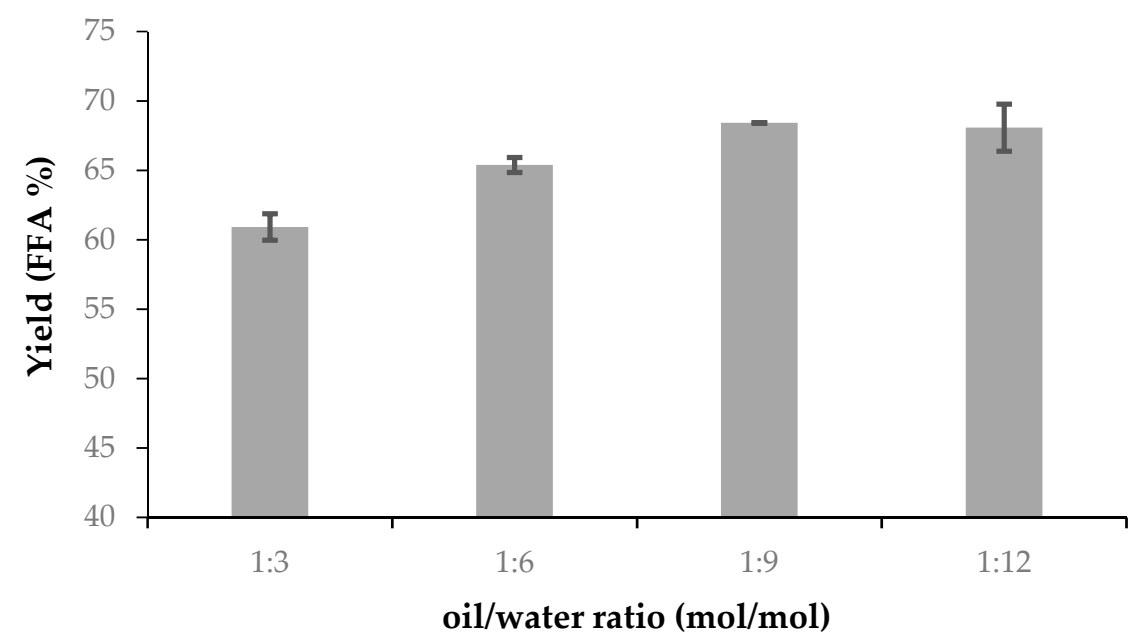

Figure 7. Hydrolysis of soybean oil using different oil/water molar ratios. Reaction conditions: $1 \mathrm{mmoL}$ of soybean oil, $1 \mathrm{~mL}$ n-heptane, $10 \%$ of biocatalyst based on soybean oil mass, $30^{\circ} \mathrm{C}$, and $5 \mathrm{~h}$.

The effect of the reaction temperature on the soybean oil hydrolysis catalyzed by ASL was studied in the range $20-60{ }^{\circ} \mathrm{C}$. Figure 8 presents the results. An optimal ASL activity can be observed at $30{ }^{\circ} \mathrm{C}$. 


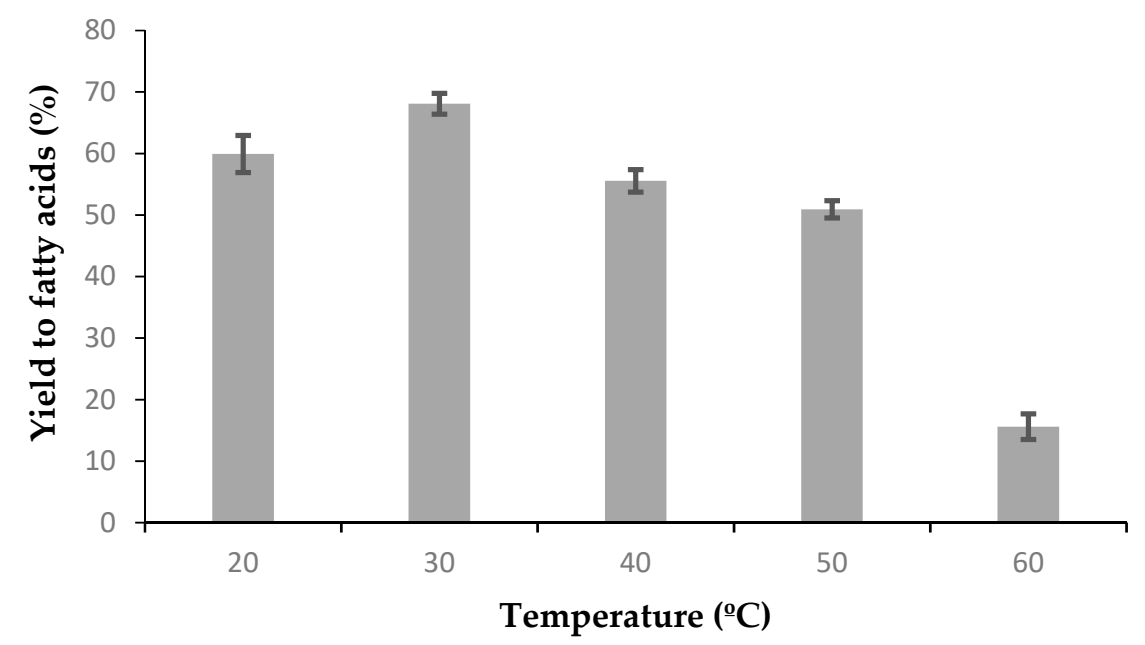

Figure 8. Hydrolysis of soybean oil at different reaction temperatures. Reaction conditions: $1 \mathrm{mmoL}$ of soybean oil, $9 \mathrm{mmoL}$ of water, $1 \mathrm{~mL}$-heptane, $5 \mathrm{~h}$, and $10 \%$ of biocatalyst based on soybean oil mass.

The optimum biocatalyst loading for the hydrolysis of soybean oil was studied adjusting the ASL mass in the range $0-15 \%$ based on soybean oil mass. Figure 9 presents the results and shows a constant yield to fatty acids $(68 \%)$ when $10 \%$ or higher concentration of ASL was used.

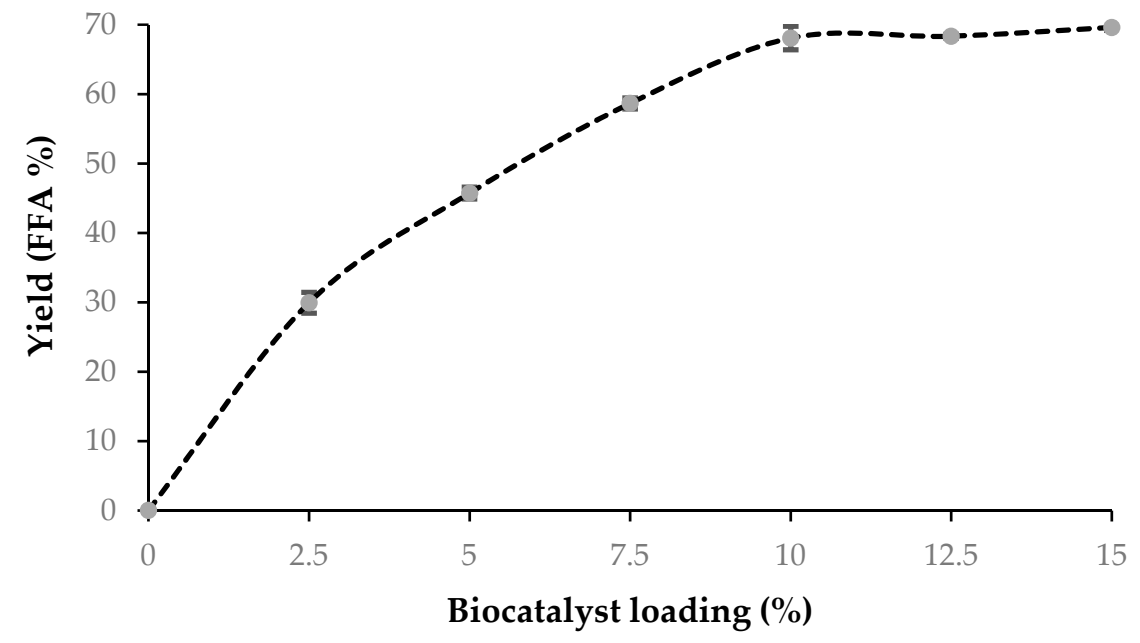

Figure 9. Hydrolysis of soybean oil using different biocatalyst loading. Reaction conditions: $1 \mathrm{mmol}$ of soybean oil, $9 \mathrm{mmoL}$ of water, $1 \mathrm{~mL}$-heptane, $30^{\circ} \mathrm{C}$, and $5 \mathrm{~h}$.

The hydrolysis reaction of soybean oil was carried out as a function of time under the optimum conditions previously determined: Oil/water molar ratio (moL/moL): $1: 9,10 \%$ of biocatalyst, and $30^{\circ} \mathrm{C}$. Figure 10 shows the yield to free fatty acids as a function of time. A continuous increasing curve was found, with a maximum yield of $68 \%$ after $5 \mathrm{~h}$ of reaction. 


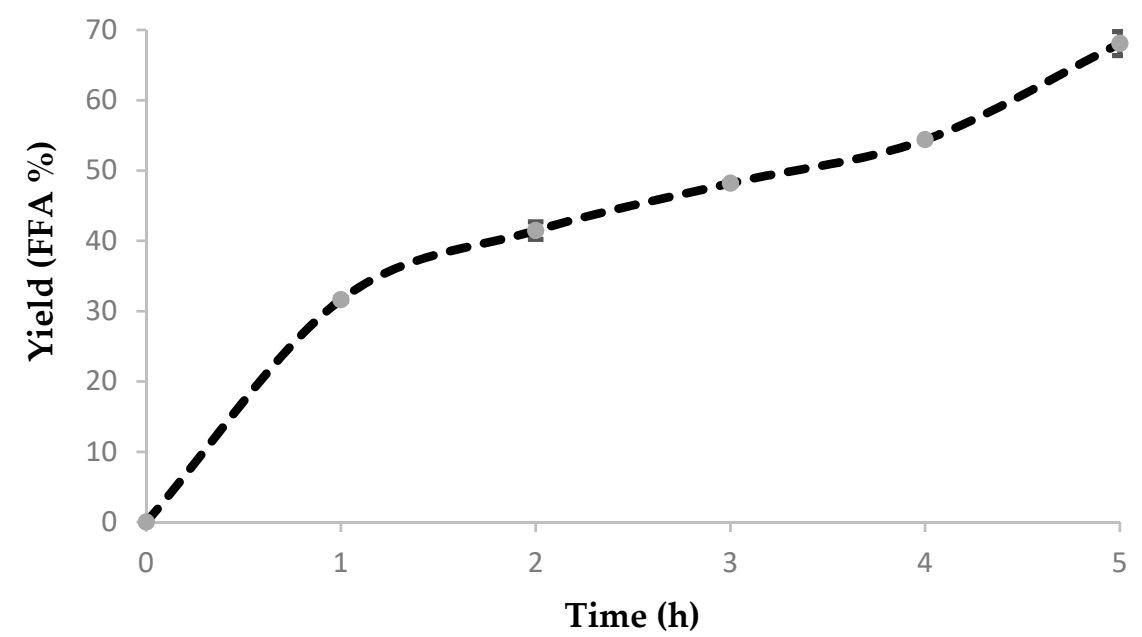

Figure 10. Hydrolysis of soybean oil under optimal conditions. Evaluation of the reaction time. Reaction conditions: $1 \mathrm{mmoL}$ of oleic acid, $9 \mathrm{mmoL}$ of water, $1 \mathrm{~mL}$-heptane, $10 \%$ of biocatalyst based on soybean oil mass, and $30{ }^{\circ} \mathrm{C}$.

The performance of ASL in the triglycerides hydrolysis was compared with commercial biocatalysts (Novozym 435, Lipozyme RM IM and Lipozyme TL IM), using soybean oil as substrate. Figure 11 shows the evolution of the yield of the free fatty acids produced with the reaction time. ASL showed the best performance of all the biocatalysts tested $(42 \%$ at $1 \mathrm{~h}$, and the highest yield of $68 \%$ at $5 \mathrm{~h}$ ), demonstrating to be superior to the best commercial biocatalyst proved, Lipozyme TL IM (31\% after $5 \mathrm{~h})$.

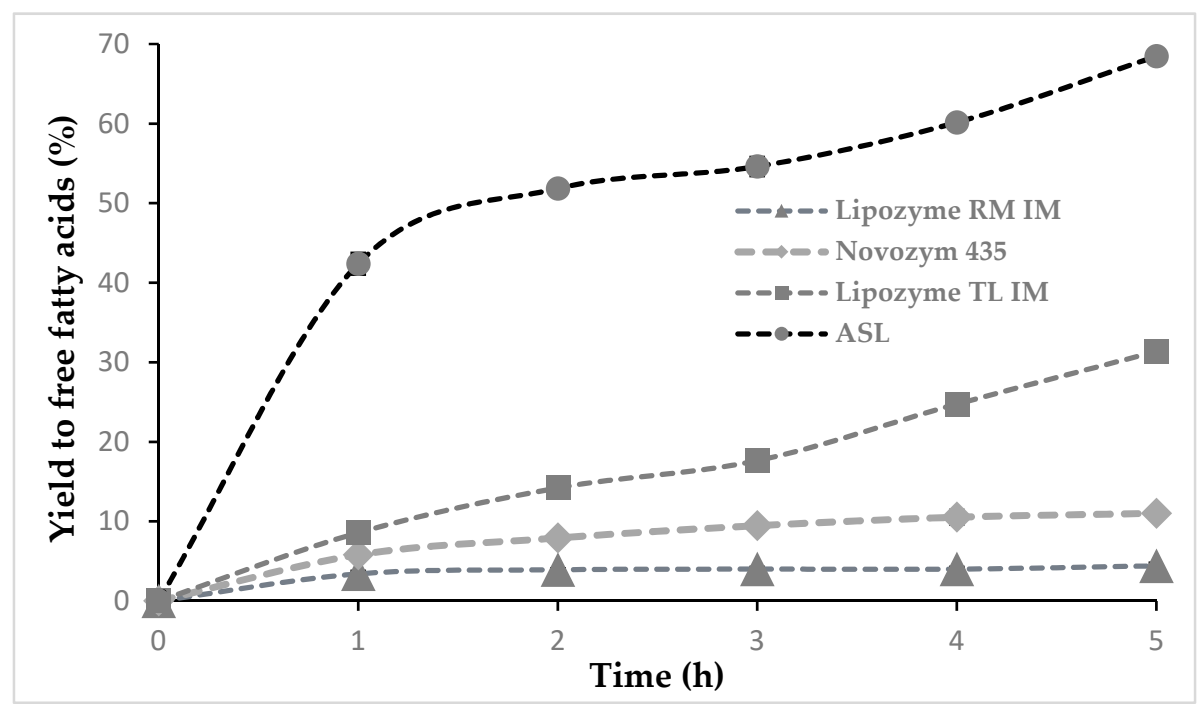

Figure 11. Hydrolysis of soybean oil using different biocatalyst. Reaction conditions: $1 \mathrm{mmoL}$ of soybean oil, $10 \mathrm{mmoL}$ of water, $1 \mathrm{~mL}$-heptane, $15 \%$ of biocatalyst based on soybean oil mass, and $30^{\circ} \mathrm{C}$. Biocatalyst: ASL, Novozym 435, Lipozyme RM IM, Lipozyme TL IM.

\subsection{Hydrolysis of p-nitrophenyl of Carboxylic Esters}

The biocatalyst ASL was studied in the hydrolysis of p-nitrophenyl laurate and palmitate esters, also comparing its performance with that of the commercial biocatalyst Novozym 435, Lipozyme RM IM and Lipozyme TL IM. Figures 12 and 13 show the activity of the tested biocatalysts for the hydrolysis of p-nitrophenyl laurate and palmitate, respectively. From both figures, it was observed that ASL had the best activity for the hydrolysis of p-nitrophenyl laurate $\left(8 \times 10^{-4} \mathrm{UI} / \mathrm{mg}\right)$, being Novozym 435 the catalyst with the second best activity $\left(4 \times 10^{-4} \mathrm{UI} / \mathrm{mg}\right)$. When the substrate is 
p-nitrophenyl palmitate, ASL showed an activity similar to the one presented by Lipozyme RM IM, and the best performance was displayed by Lipozyme TL IM.

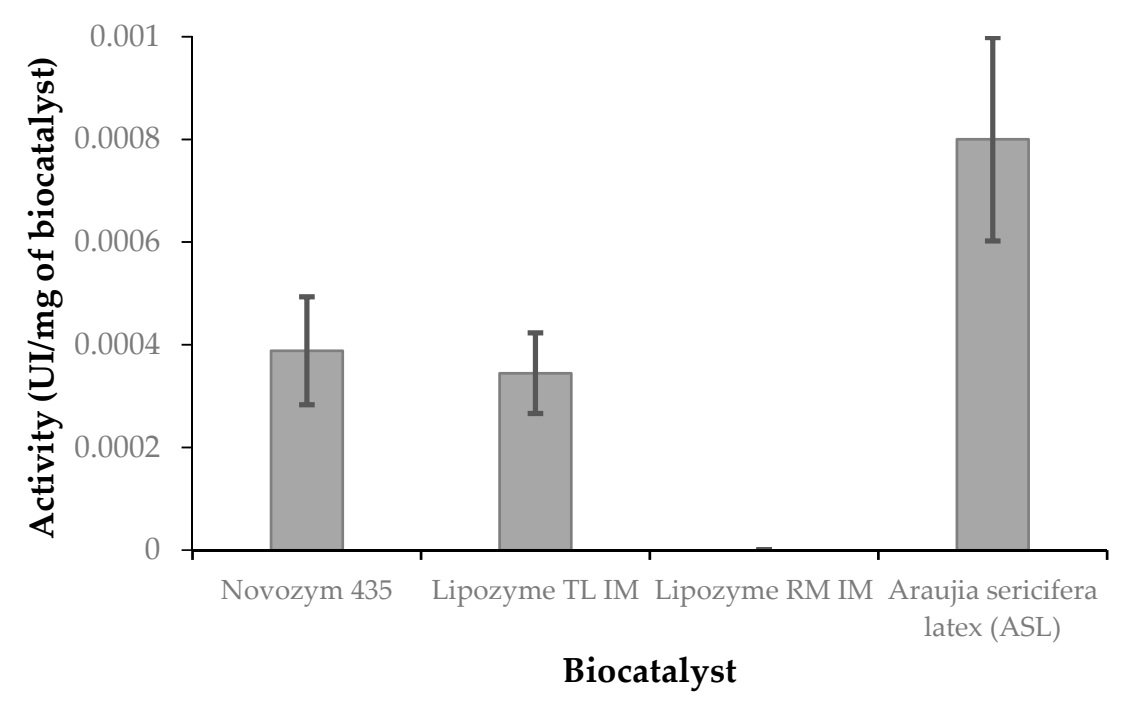

Figure 12. Hydrolysis of $p$-nitrophenyl laurate using different biocatalyst ( $\mathrm{pH} 8.0,0.1 \mathrm{M}$ Tris- $\mathrm{HCl}$, $0.0075 \%(v / v)$ Triton $\mathrm{X}-100,30^{\circ} \mathrm{C}, 5 \mathrm{mg}$ of biocatalyst, and $\left.6 \mathrm{~min}\right)$.

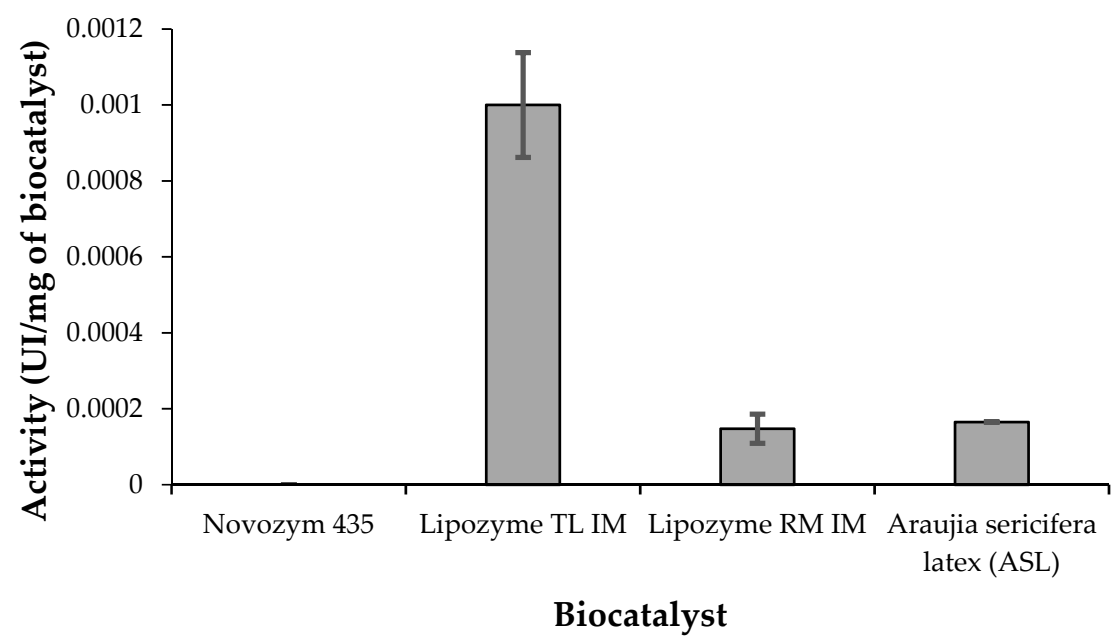

Figure 13. Hydrolysis of $p$-nitrophenyl palmitate using different biocatalyst $(\mathrm{pH}$ 8.0, $0.1 \mathrm{M}$ Tris- $\mathrm{HCl}$, $0.0075 \%(v / v)$ Triton $\mathrm{X}-100,30^{\circ} \mathrm{C}, 2.5 \mathrm{mg}$ of biocatalyst, and $\left.10 \mathrm{~min}\right)$.

\section{Discussion}

ASL has been demonstrated to be a highly active biocatalyst in soybean oil hydrolysis to fatty acids, and in esterification, at a temperature as low as $30^{\circ} \mathrm{C}$. The apparent alterations in the trend found in the tested reactions, for example for the esterification of oleic acid with alcohols with different carbon chain length, could be assigned to the multienzymatic character of the ASL system. Previous results indicated that in this complex biocatalyst, there are lipases, proteases and phospholipases (unpublished results from our group). These enzymes may also have a promiscuous activity for different substrates. With this idea in mind, proteases may show hydrolytic activity, lipases may have peptidase and phospholipase activity and phospholipases may contribute to hydrolytic and esterase activity. Each group of enzymes has its own vulnerabilities to inhibitors and its own response to different kinds of steric hindrance in substrates or to different solvents as reaction media. This is the reason why the latex of $A$. sericifera was analyzed as a complete enzymatic system, complex and difficult to characterize. 
One of the most interesting results was the high enzymatic activity of ASL at temperatures as low as $30^{\circ} \mathrm{C}$. Generally, commercial lipases of fungal or bacterial sources have their optimum temperatures at $60-70^{\circ} \mathrm{C}$, near the denaturation temperature for proteins. In this case, however, even when it seems intuitively right (because plants generally can't face temperatures higher than $45-50{ }^{\circ} \mathrm{C}$ ), it becomes practically advantageous and not necessarily expected. The open door to optimization of activity at low temperatures is a clear advantage of ASL compared to commercial lipases, including those from Novozymes ${ }^{\circledR}$ or other leading companies in the market.

The profile of conversion of OA in the esterification reaction versus the amount of ASL follows the common pattern found for most of the immobilized lipases in this reaction. The equilibrium conversion was probably reached, even when the aggregation phenomena may be present, but the main point is that the OA conversion reaches $90 \%$, at $30{ }^{\circ} \mathrm{C}$, with no more than $10 \% \mathrm{w} / \mathrm{w}$ of the biocatalyst. The optimum initial molar ratio OA/OL was 1:2, further adding of octanol decreased the activity. The role of alcohols as inhibitors of lipases may be present here. Besides this, the use of EDTA during the extraction of the latex may increase the steric hindrance around the active sites of the enzymes. The comparative profile of ASL and commercial lipases shown in Figure 6 shows that under the same operating conditions, ASL achieved the highest conversion in $4 \mathrm{~h}$, whereas the commercial lipases did the same in $2 \mathrm{~h}$. Taking into account that Novozym 435 costs approx. 78 USD per gram (Sigma), the relative cost of ASL is near 100 times lower, therefore the increase of energetic cost is marginally compensated. ASL would be very useful in an oil-based refinery considering then its low cost and high versatility.

When analyzing soybean oil hydrolysis to fatty acids, the trend is evident: High hydrolytic activity at low temperatures with not more than a 9:1-10:1 water to oil molar ratio, not more than 10\% biocatalyst and after only $5 \mathrm{~h}$. Figure 11 shows clearly the advantage of the use of ASL comparatively to even one of the most effective and active commercial lipases: Lipozyme TL IM (based on Thermomyces lanuginose lipase).

Finally, looking at the hydrolytic activity considering $p$-nitrophenol esters, a very interesting pattern was found. With $p$-nitrophenyl laurate, Novozym 435 and Lipozyme TL IM showed similar activity, whereas ASL was more active, twice as much with respect to commercial biocatalyst. With $p$-nitrophenyl palmitate, ASL and Lipozyme RM IM presented similar activity, whereas Lipozyme TL IM showed the highest activity. It seems that ASL has high preference for medium chain fatty acids (such as lauric acid or laurate in esters) whereas the commercial lipases show preference to long chain fatty acids (such as palmitic acid or palmitate in esters). ASL seems to be selective then to medium-chain fatty acids and this experimental finding may be very interesting in the field of synthesis of structured triglycerides or in the recovering of different fatty acids from mixtures (i.e., by esterification).

Future research could expand the application of ASL to the production of high added value products from biomass and to the fields of biopolymer synthesis, such as polyesters from diacids, among others.

Supplementary Materials: The following are available online at http://www.mdpi.com/2311-5637/5/1/18/s1.

Author Contributions: D.A.S. planned the study, D.A.S., M.E.F. and S.R.M. performed the experiment, D.A.S. processed the data, G.M.T. and M.L.F. analyzed the data and wrote the manuscript, D.A.S., M.E.F., S.R.M., G.M.T., and M.L.F. revised the manuscript, M.L.F., and G.M.T. obtained the funds for this investigation.

Funding: This research was funded by the Agencia Nacional de Promoción Científica y Tecnológica (National Agency of Scientific and Technological Promotion, Argentina), grants PICT 2015-932/1583 and PICT CABBIO 2016-4687, and the Universidad Nacional del Sur, grant PGI 24/M141.

Acknowledgments: The authors thank the Agencia Nacional de Promoción Científica y Tecnológica (National Agency of Scientific and Technological Promotion, Argentina), the Consejo Nacional de Investigaciones Científicas y Técnicas (National Council for Scientific and Technological Research, CONICET), and the Universidad Nacional del Sur. M.E.F. is postdoctoral fellowship of CONICET. D.A.S., S.R.M., G.M.T., and M.L.F. belong to the CONICET Researcher Career.

Conflicts of Interest: The authors declare no conflict of interest. 


\section{References}

1. De Jong, E.; Jungmeier, G. Biorefinery Concepts in Comparison to Petrochemical Refineries. In Industrial Biorefineries and White Biotechnology; Ashok Pandey, A., Höfer, R., Taherzadeh, M., Nampoothiri, K., Larroche, C., Eds.; Elsevier B.V.: Amsterdam, The Netherlands, 2015; pp. 3-33.

2. Moncada, J.; Cardona, C.; Rincón, L. Design and analysis of a second and third generation biorefinery: The case of castorbean and microalgae. Bioresour. Technol. 2015, 198, 836-843. [CrossRef] [PubMed]

3. Hassana, S.; Williams, G.; Jaiswal, A. Moving towards the second generation of lignocellulosic biorefineries in the EU: Drivers, challenges, and opportunities. Renew. Sustain. Energy Rev. 2019, 101, 590-599. [CrossRef]

4. Rincón, L.; Moncada, J.; Cardona, C. Analysis of potential technological schemes for the development of oil palm industry in Colombia: A biorefinery point of view Industrial. Crop. Prod. 2014, 52, 457-465. [CrossRef]

5. Abdelmoez, W.; Mustafa, A. Oleochemical industry future through biotechnology. J. Oleo Sci. 2014, 63, 545-554. [CrossRef] [PubMed]

6. Hasan, F.; Shah, A.A.; Hameed, A. Industrial applications of microbial lipases. Enzym. Microb. Technol. 2006, 39, 235-251. [CrossRef]

7. Mounguengui, R.W.M.; Brunschwig, C.; Baréa, B.; Villeneuve, P.; Blin, J. Are plant lipases a promising alternative to catalyze transesterification for biodiesel production? Prog. Energy Combust. Sci. 2013, 39, 441-456. [CrossRef]

8. Bucciarelli, A.; Cambi, V.; Villamil, C. Morfoanatomía de Araujia hortorum E. Fourn. (Asclepiadaceae), especie nativa de interés medicinal. Phyton (Buenos Aires) 2008, 77, 283-295.

9. Morcelle, S.; Cánepa, A.; Padró, J.; Llerena-Suster, C.; Clapés, P. Syntheses of dipeptide alcohols and dipeptide aldehyde precursors catalyzed by plant cysteine peptidases. J. Mol. Catal. B Enzym. 2013, 89, 130-136. [CrossRef]

10. Morcelle, S.; Liggieri, C.; Bruno, M.; Priolo, N.; Clapés, P. Screening of plant peptidases for the synthesis of arginine-based surfactants. J. Mol. Catal. B Enzym. 2009, 57, 177-182. [CrossRef]

11. Obregón, W.; Liggieri, C.; Morcelle, S.; Trejo, S.; Avilé, F.; Priolo, N. Biochemical and PMF MALDI-TOF analyses of two novel papain-like proteinases. Protein Pept. Lett. 2009, 16, 1323-1333. [CrossRef] [PubMed]

12. Matkovic, S.; Nilsson, J.; Fait, M.; Morcelle, S.; Briand, L. Screening of novel materials for biodiesel production through the esterification of oleic acid. Catal. Lett. 2016, 146, 2341-2347. [CrossRef]

13. Di Santo Meztler, P.; Fait, M.E.; Foresti, M.L.; Morcelle, S.R. Biocatalytic characterization of a naturally immobilized lipase found in Araujia sericifera Brot.(Apocynaceae) latex. Catal. Sci. Technol. 2014, 4, 1386-1394. [CrossRef]

14. Rashid, N.; Shimada, Y.; Ezaki, S.; Atomi, H.; Imanaka, T. Low-temperature lipase from psychrotrophic Pseudomonas sp. strain KB700A. Appl. Environ. Microbiol. 2001, 67, 4064-4069. [CrossRef] [PubMed] 